\title{
Design and monitoring body temperature and heart rate in humans based on WSN using star topology
}

\author{
Setiyo Budiyanto', Freddy Artadima Silaban², Lukman Medriavin Silalahi ${ }^{3}$, Selamet Kurniawan $^{4}$, \\ Fajar Rahayu I. $\mathbf{M}^{5}$, Ucuk Darusalam ${ }^{6}$, Septi Andryana ${ }^{7}$ \\ 1,2,3,4 Department of Electrical Engineering, Universitas Mercu Buana, Jakarta, Indonesia \\ ${ }^{5}$ Department of Electrical Engineering, Universitas Pembangunan Nasional "Veteran", Jakarta, Indonesia \\ ${ }^{6,7}$ Department of Informatics Engineering, Universitas Nasional, Jakarta, Indonesia
}

\begin{tabular}{|c|c|}
\hline Article Info & ABSTRACT \\
\hline Article history: & \multirow{10}{*}{$\begin{array}{l}\text { Electronic health (E-health) uses information and communication technology } \\
\text { including electronics, telecommunications, computers, and informatics to } \\
\text { process various types of medical information, to carry out clinical services } \\
\text { (diagnosis or therapy). Health is the most important asset in human life, } \\
\text { therefore maintaining health is a top priority and serious attention needed. } \\
\text { Heart rate and body temperature are vital signs that the hospital routinely } \\
\text { checks for clinical signs and are useful for strengthening the diagnosis of a } \\
\text { disease. In this research monitoring heart rate and body temperature with the } \\
\text { wireless sensor network (WSN) method that uses NodeMCU } 1.0 \text { as a } \\
\text { controller module and wireless as communication between nodes, the } \\
\text { wireless network used in this research Wi-Fi network. As a data taker, a } \\
\text { DS18b20 temperature sensor and a heart rate sensor (pulse sensor) are } \\
\text { needed, which will be displayed by the ThingSpeak web and smartphones. } \\
\text { From the test results, the success rate of the system in detecting heart rates is } \\
97.17 \% \text {. Whereas in detecting body temperature the success rate of the } \\
\text { system is } 99.28 \% \text {. For data transmission, the system can send data smoothly } \\
\text { at a maximum distance of } 15 \text { meters with a barrier. }\end{array}$} \\
\hline Received Mar 25, 2020 & \\
\hline Revised Oct 10, 2020 & \\
\hline Accepted Dec 5, 2020 & \\
\hline Keywords: & \\
\hline DS18b20 & \\
\hline Electronic health & \\
\hline NodeMCU 1.0 & \\
\hline Web thingspeak & \\
\hline WSN & \\
\hline
\end{tabular}

This is an open access article under the CC BY-SA license.

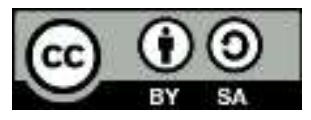

\section{Corresponding Author:}

Freddy Artadima Silaban

Department of Electrical Engineering

Universitas Mercu Buana

Jl. Meruya Selatan No.1, Kembangan, Jakarta Barat 11650, Indonesia

Email: freddy.artadima@mercubuana.ac.id

\section{INTRODUCTION}

E-Health one of the implementation technology in the world of health. According to (WHO, 2016), e-health uses electronic equipment to manage health resources and maintain health. Broadly speaking, ehealth covers three main areas, the first for the delivery of health information for health professionals and users of health information using the internet and telecommunications equipment. The second, e-health utilizes the development of information technology and e-commerce to improve health services. The third, ehealth uses e-commerce and e-business to manage the health system. Many researchers about health, one of which is monitoring heart rate and body temperature [1-4].

Health is the most important asset in human life, therefore maintaining health is a top priority and serious attention is needed. The field of health sciences is developing very rapidly both in terms of medicine and other supporting scientific fields such as pharmacy, chemistry, biology and so on [5-6]. In previous research monitoring heart rate and body temperature developed a device used arduino board connected with a 
heart rate sensor, GSM modem, and GPS. The heart rate sensor is mounted on the fingertips, hand performances or on the auricle. The sensor detects a human heartbeat which is then processed by Arduino so that it can be represented in the form of beat/minute (BPM) [7-8].

In the process, the examination of heart rate and body temperature in several hospitals still uses a manual system where a nurse must come to the patient's room to see and record the patient's heart rate and temperature. This system is less effective because it takes a lot of time. In this research, a wireless heart rate and human body temperature monitoring system was created [9-10]. The heart is organ form of a muscle, cone-shaped, hollow, with the base above and its peak below it tilted to the left. When blood is pumped out of the heart in an artery, known as a palpable artery, a pulse wave, and this pulse can also be felt in the place where arteries pass, for example, the radial artery in front of the wrist and fingertips. When this situation, the volume of blood at the tip of the finger increases or clots. Then conversely when the heart does not pump blood the volume of blood at the fingertips becomes smaller [11-12].

Body temperature is a balance between heat production and expenditure from the body, which is measured in units of heat called degrees. The temperature in question is the heat or cold of a substance. Body temperature is the difference between the amount of heat produced by body processes and the amount of heat loss to the outside environment. So the difference between the heat produced and body heat expenditure is body temperature because body temperature is a reflection of body heat [13-14]. In the condition of the body that performs a strenuous physical activity, the human temperature control mechanism keeps the core temperature or the temperature of the inner tissue relatively constant, although the outside temperature fluctuates the body temperature still depends on blood flow to the skin and the amount of heat loss to the outside environment. Due to temperature fluctuations in the environment, acceptable normal body temperatures range from $36^{\circ} \mathrm{C}$ to $38^{\circ} \mathrm{C}[15-20]$.

Researchers monitor heart rate and body temperature using the wireless sensor network (WSN) method that uses NodeMCU 1.0 as a controller module and wireless as communication between nodes, the wireless network used in this research is Wi-Fi network. As a data taker, a DS18b20 temperature sensor and a heart rate sensor (pulse sensor) are needed, which will be displayed via the Thingspeak web and smartphones [21-23]. By applying star topology, MCU Node technology and Thingspeak facilitate the performance the medical team to monitor, maintain, diagnose and manage health data, especially in body temperature and human heart rate [24-26]. From the test results, the success rate of the system in detecting heart rates is $97.17 \%$. Whereas in detecting body temperature the success rate of the system is $99.28 \%$. For data transmission, the system can send data smoothly at a maximum distance of 15 meters with a barrier. For storage in a database, the system can store heart rate and body temperature data as expected.

\section{RESEARCH METHOD}

The design of monitoring body temperature and heart rate in humans with the application of Thingspeak with the wireless sensor network (WSN) method needs to pay attention to several things that must be considered, such as sensors on body temperature, sensors on heart rates, microcontrollers. How the quality of service (QoS) of the network at a certain distance within the range of NodeMCU on the Wireless Sensor Network is implemented, parameters that must be considered in monitoring body temperature and heart rate in humans with Thingspeak application with wireless sensor network (WSN) system, and monitoring via website thing speak with an IoT-based wireless sensor network system in monitoring body temperature and heart rate in health can overcome and provide solutions to the world of health. implementing this system is useful to facilitate the performance of the medical team to monitor, maintain, diagnose and manage health data, especially in human body temperature and heart rate.

\subsection{System prototype design method}

The system design stage consists of four (4) main stages, namely:

a) Architectural design of the system monitoring the condition of body temperature in humans and monitoring the heartbeat frequency in humans.

b) Design of the station node.

c) Design of the node coordinator.

d) Design of the interface application through the smartphone application media and also Website-based application interface.

the design of the system communication architecture is carried out in a star topology, where the end device (station node) is connected directly (direct communication) to the controller and monitor (node coordinator).

Implementation of coordinator nodes in the research of 1 (one) coordinator node, which is Thingspeak which is also a provider of interface applications through the website, Thingspeak on the coordinator node is a data storage service on the server that can also be a controller and monitor of the node 
Station by utilizing communication Wi-Fi in NodeMcu at the station node in the field. The implementation of station nodes in the field in this research made 2 (two) station nodes consisting of 1 station node initialized station node 1 and 1 other station node initialized station node 2 which is intended for the pulse sensor module and DS18B20 sensor (implemented on the end device on the station node side 1 and side 2 of the coordinator node), the design of the system architecture with the star topology is shown in Figure 1.

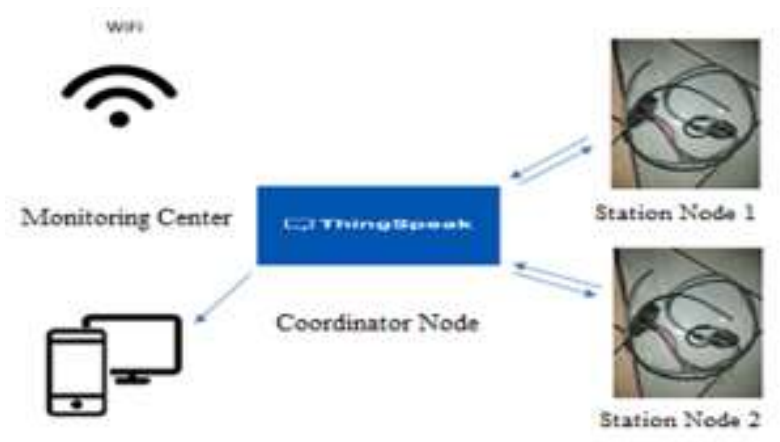

Figure 1. System architecture with star topology

The prototype system in this research is defined as an integrated device so that it can carry out the process of data acquisition in real terms from the results of recording information at the node of each station in the form of values of temperature parameters of body temperature and heart rate (node stations 1 and 2). Data recorded by the station node that is placed in a predetermined field is transmitted through the Wi-Fi network with the star topology method to the coordinator node as the controller and monitor, then the information is transmitted to the server. Data is displayed through the website interface application and the Smart Phone application.

\subsection{Data acquisition}

The data acquisition process carried out by MCU 1.0 Node microcontroller which is placed in each station node namely station node 1 and station node 2 . The data recorded by each sensor in the field in realtime, are acquired through MCU node 1.0 at each station node. At node stations 1 and 2, the process of data acquisition by the microcontroller Node MCU1.0 is recording or collecting data in the form of human body temperature $\left({ }^{\circ} \mathrm{C}\right)$ and heart rate frequency detected by the heart rate sensor module and the pulse sensor module, these data then transmitted over the wifi network on the star topology directly to the coordinator node for further data processing. Data is then displayed through the website and smartphone interface applications.

\subsection{System testing method}

The testing method and analyzing system performance through a smartphone application interface connected to the coordinator node are done through a monitoring center. In this study, the system warning limits are applied to the temperature and heart rate phenomena that change. Analysis and measurements are carried out through the heart rate module and body temperature which is implemented in it the pulse sensor module as a sensor that detects the heartbeat and the DS18B20 module as the sensor detects body temperature with a normal heart rate limit which is between $60 \mathrm{bpm}$ to $100 \mathrm{bpm}$, the beat disturbed heart which is less than $60 \mathrm{bpm}$ and more than $100 \mathrm{bpm}$, and normal body temperature which is between $36{ }^{\circ} \mathrm{C}$ to $37{ }^{\circ} \mathrm{C}$, disturbed body temperature which is less than $36{ }^{\circ} \mathrm{C}$ and more than $37{ }^{\circ} \mathrm{C}$. If one of the boundary indicators is met, the node coordinator module conveys information messages of phenomena that occur to the monitoring center via WiFi communication to users as monitors.

\section{RESULTS AND DISCUSSION}

\subsection{Station node design implementation}

Station node is a set of the hardware placed in the field to acquire and record data in the form of body temperature and heart rate data from the sensor module implemented in it and the information is then forwarded to the coordinator node. Station nodes designed in this research are station node 1 and station node 2. The pulse sensor module is a module that utilizes infrared waves, LED power indicators and LED signal 
indicators. The voltage supply for pulse sensor modules ranges from $3.3 \mathrm{~V}$ to $5 \mathrm{~V}$ (optional). The output of the pulse sensor module is a digital logic quantity through port D1 that is connected to the microcontroller. Output port D0 is the logic value "1" if there is a "Beat" vibration detected by the sensor and vice versa output will be the logic value "0" if no heartbeat is detected. It also consists of a DS18B20 sensor in the form of a Thermo Couple which is sensitive to temperature, in use it requires a resistor as a load to connect to data. Figure 2 shows the architecture of station nodes 1 and 2 which have the same sensor.

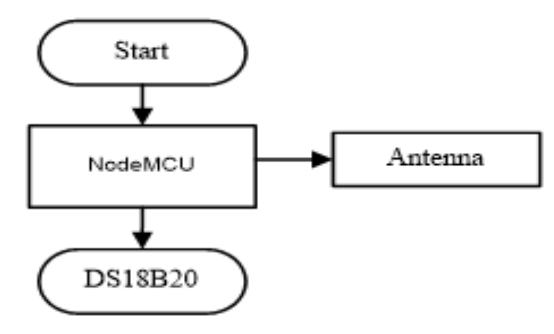

Figure 2. Architecture of Station Nodes 1 and 2

The NodeMcu module is designed to acquire, record, transmit and process sensor data. The NodeMcu module on the system is programmed through the Arduino integrated development environment (IDE) software. Arduino IDE is used to write, edit code, enter function formulas and change the code into Arduino devices. The programming language is Arduino IDE $\mathrm{C} / \mathrm{C}++$. The Arduino IDE transfers instructions to the Arduino board or upload process.

\subsection{Heartbeat frequency analysis and measurement}

Data from the acquisition of station nodes 2 and 1 are sent to the coordinator node and monitored through the monitoring center, in the form of a measured heart rate frequency on the system as shown in Table 1, measurements are taken here for 1 day on October 9, 2019, and the time for measurement and analysis is 12 hours from 15.00 WIB-02.00 WIB with shaving on the same object.

Node stations 2 and 1 are sent to the coordinator node and monitored through the monitoring center, in the form of measured body temperature in the system, measurement here for 1 day on October 9, 2019, and the time for measuring and analyzing for 12 hours from 15.00 WIB-02.00 WIB with shaving on the same object. The measurement results on the stethoscope mean object 1 is $79.6 \mathrm{bpm}$ and object 2 is 83.75 , whereas if the measurement uses a pulse sensor the average object 1 is $79.3 \mathrm{bpm}$, and object 2 is $84.75 \mathrm{bpm}$.

Table 1. Measurement of heartbeat frequency in nodes 1 and nodes 2

\begin{tabular}{|c|c|c|c|c|c|}
\hline \multirow[t]{2}{*}{ No } & \multirow[t]{2}{*}{ Time } & \multicolumn{2}{|c|}{$\begin{array}{l}\text { Heart rate is measured in real time } \\
\text { using a stethoscope (bpm) }\end{array}$} & \multicolumn{2}{|c|}{$\begin{array}{l}\text { The average heart rate using a pulse } \\
\text { sensor (bpm) }\end{array}$} \\
\hline & & Object 1 & Object 2 & Object 1 & Object 2 \\
\hline 1 & 15.00WIB & 78 & 80 & 76 & 80 \\
\hline 2 & 16.00WIB & 75 & 91 & 75 & 94 \\
\hline 3 & 17.00WIB & 85 & 74 & 85 & 73 \\
\hline 4 & 18.00WIB & 85 & 96 & 87 & 98 \\
\hline 5 & 19.00WIB & 83 & 73 & 81 & 74 \\
\hline 6 & 20.00WIB & 74 & 68 & 75 & 68 \\
\hline 7 & 21.00WIB & 88 & 93 & 87 & 98 \\
\hline 8 & $22.00 \mathrm{WIB}$ & 67 & 80 & 64 & 78 \\
\hline 9 & 23.00WIB & 77 & 80 & 78 & 79 \\
\hline 10 & 24.00WIB & 79 & 85 & 77 & 89 \\
\hline 11 & 01.00WIB & 85 & 90 & 86 & 92 \\
\hline 12 & 02.00WIB & 80 & 95 & 81 & 94 \\
\hline
\end{tabular}

\subsection{Analysis and measurement of response time and sensitivity of system performance detecting body temperature}

Data from the acquisition of the station 1 node is sent to the coordinator node and monitored through the monitoring center, in the form of measured degrees Celsius $\left({ }^{\circ} \mathrm{C}\right)$ on the system. Data in the form of calculations and analysis of the sensitivity of system performance through the response time displayed by the application interface Smartphone applications and website interface applications that can be accepted by researchers at the monitoring center. The farther the distance of the station 1 and station 2 scenarios to the 
coordinator node significantly influences the average value of the system's response time to actively respond to changes in body temperature, and the longer the node station sends a disturbance signal to the coordinator node, the longer the node response time station 2 .

It can be seen in Figure 3 that the optimal average response time value is 16.45 seconds in the measurement and analysis of the $10 \mathrm{~m}$ distance scenario of station 1 and station 2 nodes to the coordinator node, the system can detect changes in body temperature and conduct monitoring in face-to-face applications. website. The average response time value significantly increased to 18,475 seconds in the measurement and analysis of the $20 \mathrm{~m}$ distance scenario, station node 1 , and station 2 node to the coordinator node. In the measurement and scenario analysis, the distance reaches $20 \mathrm{~m}$ at station 1 node and 2 nd station node to the coordinator node, the average response time value is unstable because the coordinator node does not optimally capture the data network through Wi-Fi communication at each station node, which is 32.64 seconds, and There is an increase in time at node station 2 because node station 2 receives an interference signal from node station 1 first before sending it back to the node coordinator.

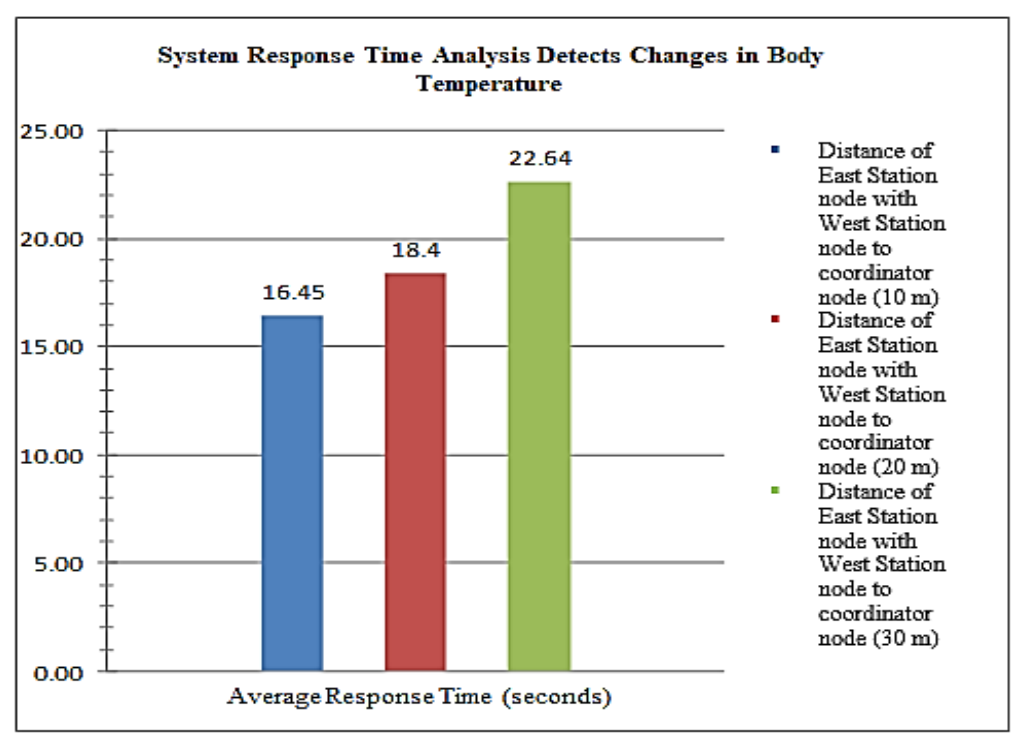

Figure 3. Graph Analysis of the System's Response Time Detecting Body Temperature

\subsection{Website-based application testing interface}

Testing and analyzing system performance through the website interface application is done by accessing Http // thingspeak.com (node coordinator) and accessing the website browser link. The first stage in monitoring system performance through the website is by going to the website thingspeak.com and then logging in using the user-id and password afterward to the intended channel. In this research, the researchers made 2 channels that were initialized with "Tool 1" and "Tool 2" which functioned as a place to store data that had been sent by the node and as a communication and controller between the node. Researchers as observers or users can monitor the performance of real-time systems through the website display displayed on the browser page. Data displayed in real-time or renewable every 10 seconds. Data that is displayed through the website page in real-time is information in the form of body temperature, heart rate frequency and the state of the sensor whether it is disturbed or not. Figure 4 shows the appearance of the website interface application when the system operates in the normal state of station node 2.

Figure 4 shows the appearance of the website interface application when the system operates in an abnormal condition. Through the body temperature sensor by using the DS18B20 sensor and the heart rate sensor that is the pulse sensor at the node station 1, detected vibration information exceeds the limit. This is indicated by the indicator field 3 indicating an increase in number 1 .

Figures 4 and 5 are monitoring media or the user can monitor the performance of the system in realtime through a website display that is displayed on a browser page. Data is displayed in real-time or updated every 10 seconds. The data displayed on the website page in real-time is information in the form of body temperature, heart rate frequency, and the state of the sensor whether it is disturbed or not. 


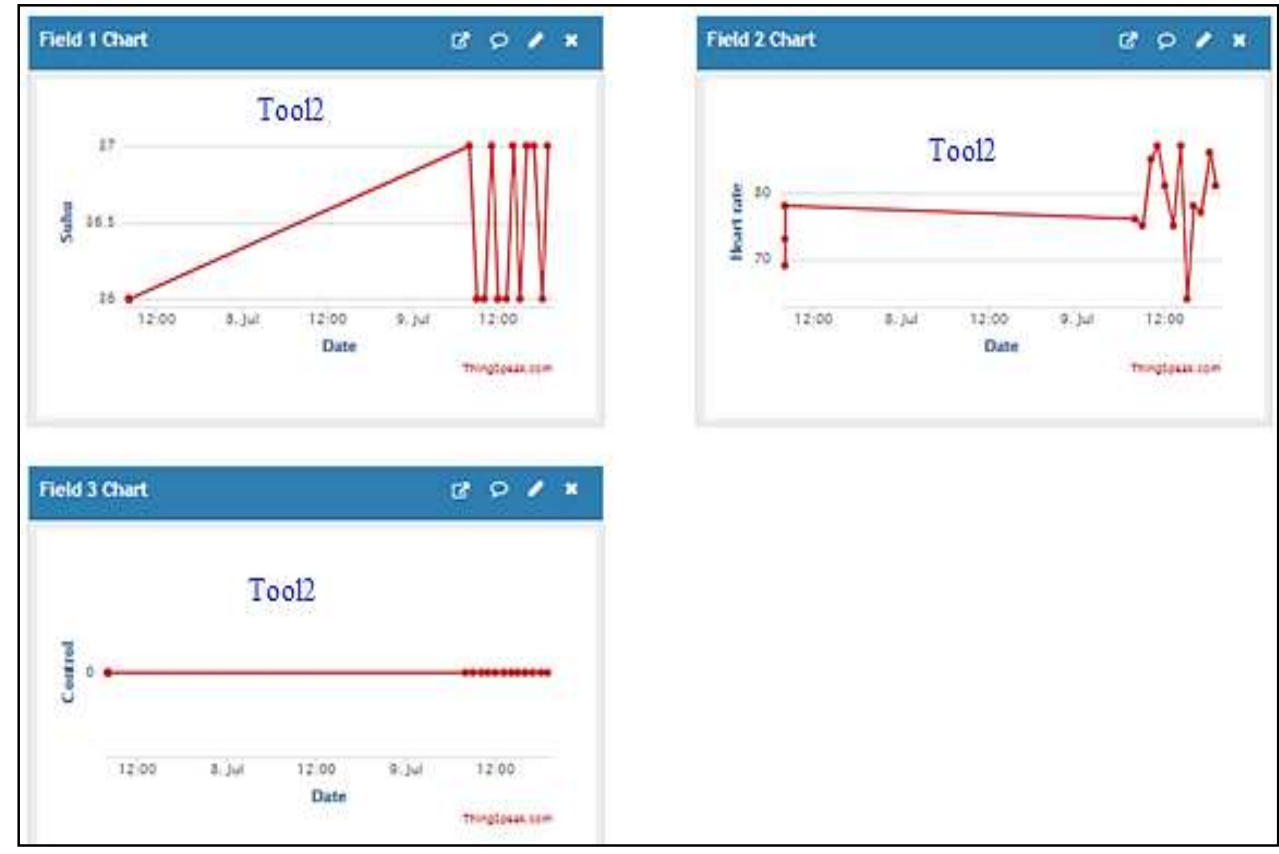

Figure 4. Website interface application display (Normal: station node 2)

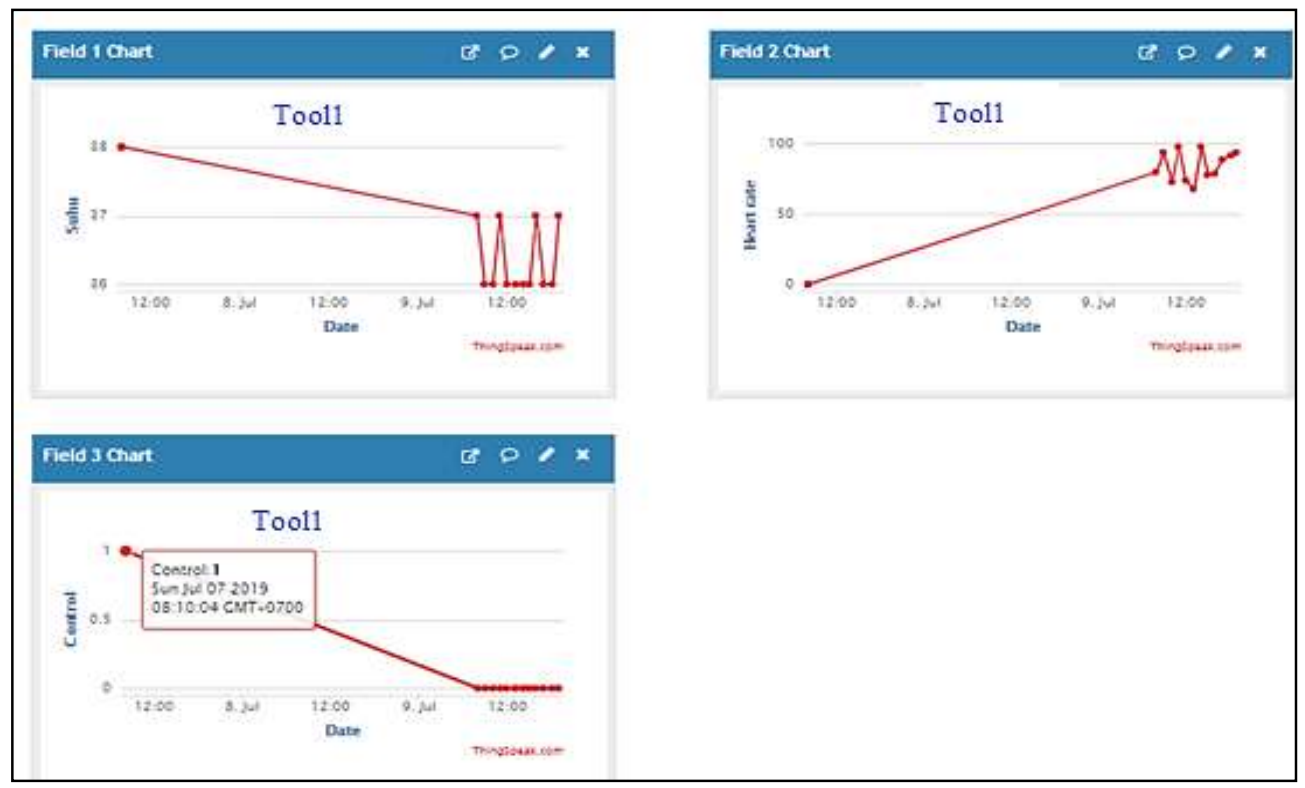

Figure 5. Website interface application display (Abnormal: station node 1)

\subsection{Application testing interface based on smartphone applications}

Testing and analyzing system performance through smartphone application-based interface applications provided by the MIT App Inventor. System work flow diagram, in which information is forwarded to the smartphone of the researcher through the application as a monitor or user at the monitoring center if one of the boundary indicators by the station node 1 and station node 2 in the system workflow diagram is fulfilled. The following are Figure 6, displaying information in the form of design drawings from the application in abnormal circumstances to researchers as monitors or users at the monitoring center to alert the process. Information in the form of text warning of disturbance values caused by body temperature or heart rate increases or decreases which will display a warning sign corresponding to the disturbed station node. It also displays the latest results from body temperature and heart rate. 


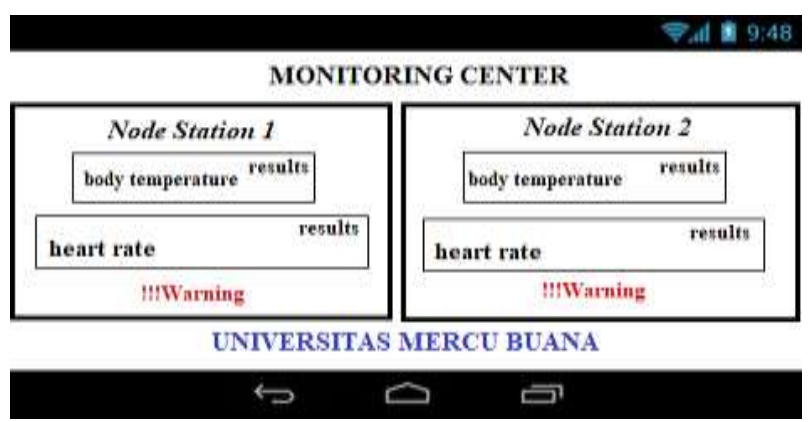

Figure 6. Display smartphone application interface (abnormal: station nodes 1 and 2)

\subsection{Analysis of system testing results}

Comparison between body temperature measurements that are measured in real terms using a thermometer and body temperature measurements using a DS18B20 sensor that will tell you how much is the error between direct measuring and measurements using DS18B20. Website-based interface application testing (http://thingspeak.com) is by the objectives of the research where it is displayed in real-time, and through the application of the smartphone, application interface displays warning information about phenomena that occur at station nodes.

\section{CONCLUSION}

We have succeeded in realizing a device for measuring body temperature and heart rate based on IoT. Both of these data were successfully sent and can be widely accessed via web pages using thingspeak.com and smartphone applications. From the results of tests that have been carried out the frequency of the heart rate is measured using an average stethoscope on object 1 and object 2 is $81.70 \mathrm{bpm}$. While the results of tests that have been carried out heart rate frequency are measured using an average pulse sensor on object 1 and object 2 is $82.04 \mathrm{bpm}$. For an average body temperature of 29.16 degrees Celsius. The success rate of the system in detecting heart rates is $97.17 \%$. Whereas in detecting body temperature the success rate of the system is $99.28 \%$. For data transmission, the system can send data smoothly at a maximum distance of 15 meters with a barrier.

\section{REFERENCES}

[1] Virone G, Wood A, Selavo L, Cao Q, Fang L, Doan T, He Z, and Stankovic J., "An advanced wireless sensor network for health monitoring," In Transdisciplinary conference on distributed diagnosis and home healthcare (D2H2), pp. 2-4, 2 Apr 2006.

[2] Aziz K, Tarapiah S, Ismail SH, and Atalla S., "Smart real-time healthcare monitoring and tracking system using GSM/GPS technologies," In Big Data and Smart City (ICBDSC), 2016 3rd MEC International Conference on, pp. 1-7, 15 Mar 2016, doi: 10.1109/ICBDSC.2016.7460394.

[3] Y. Jinging, H. Shangfu, Z. Xiao, G. Benzhen, L. Yu, D. Beibei, and L Yun,"Family Health Monitoring System Based on the Four Sessions Internet of Thingsm," in TELKOMNIKA (Telecommunication Computing Electronics and Control), vol.13, no.1, pp. 314-320, March 2015, doi: 10.12928/telkomnika.v13i1.1265.

[4] A. S. Ibrahim, Z. I. Rizman, and N. Hafizah, "Performance Analysis of Xbee-Based WSN in Various Indoor Environments," in J. Basic Appl. Sci. Res., vol. 3, no. 11, pp. 20-27, 2013.

[5] W. H. B. M. Saad, et al., "Development of Sleep Monitoring System to Observe the Effect of Room Ambient toward the Quality of Sleep," IOP Conference Series: Materials Science and Engineering, International Technical Postgraduate Conference, vol. 210, 5-6 April 2017.

[6] Latupapua Haziel, Latupapua Andrias I, Wahab Abbadi, and Alaydrus Mudrik, "Rancang Bangun Wirelees Sensor Network Berbasis Topologi Star Untuk Peringatan Dini Gempa Bumi dan Tanah Longsor," in Indonesian Journal of Electrical Engineering and Computer Science (IJEECS), ISSN : 2502-4752, pp. 437-445, 2018.

[7] Setiyo Budiyanto and Arrissetyanto Nugroho, "A New Model Of Genetic Zone Routing Protocol (GZRP): The Process Of Load Balancing and Offloading on the UMTS-IEEE 802.11g Hybrid Network," in TELKOMNIKA (Telecommunication Computing Electronics and Control), vol. 15, no. 2, pp. 598-60, June 2017, doi: 10.12928/telkomnika.v15i2.5633.

[8] A. R. R. M. Sugondo Hadiyoso, "Monitoring Photoplethysmograph Digital dengan Wireless LAN (802.11b)," in Konferensi Nasional Sistem dan Informatika, Bali, 2011. 
[9] Setiyo Budiyanto, Muhammad-Asvial, and Dadang Gunawan, "Implementation Dedicated Sensing Receiver (DSR) In 3G-Wifi Offload," In 2014 Proceeding Conference On Smart Green Technology In Electrical and Information System(ICSGTEIS), pp. 37-42, 2014, doi: 10.1109/ICSGTEIS.2014.7038731.

[10] Ibrahim N, Tomari R, Zakaria WN, and Othman N., "Non-contact Heart Rate Monitoring Analysis from Various Distances with different Face Regions," in International Journal of Electrical and Computer Engineering (IJECE), vol. 7, no. 6, pp. 3030-6, 1 Dec 2017, doi: 10.11591/ijece.v7i6.pp3030-3036.

[11] Rachman Fathur Zaini, Jamal Nurwahidah, Yanti Nur, and Purwanto Era, "Wireless Sensor Network With Mesh Topology To Control Rppm Device," in Internasional Conference On Applied Science and Technology, IEEE, 2018, doi: 10.1109/iCAST1.2018.8751589.

[12] S. M. Hassan, R. Ibrahim, K. Bingi, T. D. Chung, and N. Saad, "Application of Wireless Technology for Control: A WirelessHART Perspective," in Procedia Comput. Sci., vol. 105, no. December 2016, pp. 240-247, 2017, doi: 10.1016/j.procs.2017.01.217.

[13] E. Suter, N. Oelke, C. Adair, and G. Armitage, "Ten key principles for successful health systems integration," In Healthcare Quarterly, vol. 13, no. sp, pp. 16-23, Oct. 2009, doi: 10.12927/hcq.2009.21092.

[14] M. Iqbal, M. Fuad, H. Sukoco, and H. Alatas, "Hybrid Tree-Like Mesh Topology as New Wireless Sensor Network Platform,” In TELKOMNIKA (Telecommunication, Comput. Electron. Control), vol.14, no. 3, pp. 1166-1174, September 2016, doi: 10.12928/telkomnika.v14i3.2279.

[15] Ali NS, Alyasseri Z. A., "Wireless Sensor Network and Web Application Hybrid Scheme for Healthcare Monitoring," in Journal of Soft Computing and Decision Support Systems, vol. 4, no. 5, pp. 1-7, 19 Aug 2017.

[16] Kit C. Y., Tomari .R, Zakaria W. N., Othman .N, Safuan S. N., Yi J. A., and Sheng N. T., "Mobile based Automated Complete Blood Count (Auto-CBC) Analysis System from Blood Smeared Image," in International Journal of Electrical and Computer Engineering (IJECE), vol. 7, no. 6, pp. 3020-9, 1 Dec 2017, doi: 10.11591/ijece.v7i6.pp3020-3029.

[17] M. Young-Jae, K. Hoon-Ki, K. Yu-Ri, K. Gil-Su, P. Jongsun, and K. Soo-Won, "Design of Wavelet-Based ECG Detector for implantable actions on vo cardiac pacmakers," in Biomedical circuits and systems IEEE transactions, vol. 7, pp. 426-436, 2013, doi: 10.1109/TBCAS.2012.2229463.

[18] Santosa, Galih and Budiyanto, Setiyo, "New design of lightweight authentication protocol in wearable technology" in TELKOMNIKA (Telecommunication Computing Electronics and Control), vol. 17, p. 561. 10.12928/telkomnika.v17i2.10344, 2019, doi: 10.12928/telkomnika.v17i2.10344.

[19] Y.-T. K., B. P., G.-C. P., and Randy S. Tolentino, "A Design and Analysis Ubiquitous Healthcare Monitoring System over Wireless Sensor Network," in International Journal of Multimedia and UbiquitousEngineering, vol. 6, no. 2, pp. 55-69, 2011.

[20] Huang RY and Dung LR, "Measurement of heart rate variability using off-the-shelf smart phones," in Biomedical engineering online, vol. 15, no. 1, p. 11, Jan 2016, doi: 10.1186/s12938-016-0127-8.

[21] Setiyo Budiyanto, Muhamad Asvial, and Dadang Gunawan, "Improved Performance of Hybrid Algorithm for 3GWiFi Offload Networks," in Jurnal Teknologi (Science and Engineering)-Universiti Teknologi Malaysia, vol. 78, no. 5-9, pp. 7-11, Juni 2016, doi: 10.1186/s12938-016-0127-8.

[22] Shin KY, Lee JS, and Jang J., "Highly sensitive, wearable and wireless pressure sensor using free-standing ZnO nanoneedle/PVDF hybrid thin film for heart rate monitoring," in Nano Energy., vol. 22, pp. 95-104, 1 Apr 2016, doi: 10.1016/j.nanoen.2016.02.012.

[23] P. K. Kashyap and S. kuma, "A survey on energy efficient coverage protocols in wireless sensor networks," in International Journal of Electrical and Computer Engineering (IJECE), vol. 9, no. 2, pp. 1168-1183, 2019, doi: 10.1016/j.jksuci.2016.08.001.

[24] I. Ez-zazi, M. Arioua, A. el Oualkadi, and Y. el Assari, "Performance analysis of efficient coding schemes for wireless sensor networks," in RFID And Adaptive Wireless Sensor Networks (RAWSN), 2015 Third International Workshop on, IEEE, pp. 42-47, 2015, doi: 10.1109/RAWSN.2015.7173277.

[25] Callen J, Hordern A, Gibson K, Li L, Hains IM, and Westbrook JI, "Can technology change the work of nurses? Evaluation of a drug monitoring system for ambulatory chronic disease patients," in International Journal Of Medical Informatics, vol. 82, no. 3, pp. 159-67, 1 Mar 2013, doi: 10.1016/j.ijmedinf.2012.11.009.

[26] E. Ramadhan, A. Firdausi, and S. Budiyanto, "Design and analysis QoS VoIP using routing Border Gateway Protocol (BGP)," in 2017 International Conference on Broadband Communication, Wireless Sensors and Powering (BCWSP), Jakarta, pp. 1-4, 2017, doi: 10.1109/BCWSP.2017.8272556.

\section{BIOGRAPHIES OF AUTHORS}

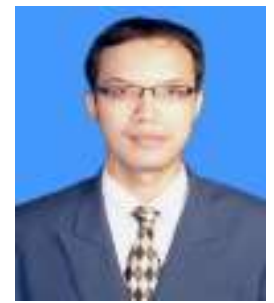

Setiyo Budiyanto is an Associate Professor in Electrical Engineering, Universitas Mercu Buana. He received his Ph.D in Electrical Engineering, Universitas Indonesia (2016). Currently he is active as a Lecturer at Universitas Mercu Buana, Jakarta (Indonesia). He conducts some research in the fields of Digital-Advanced Wireless Communication (D-AWC). 

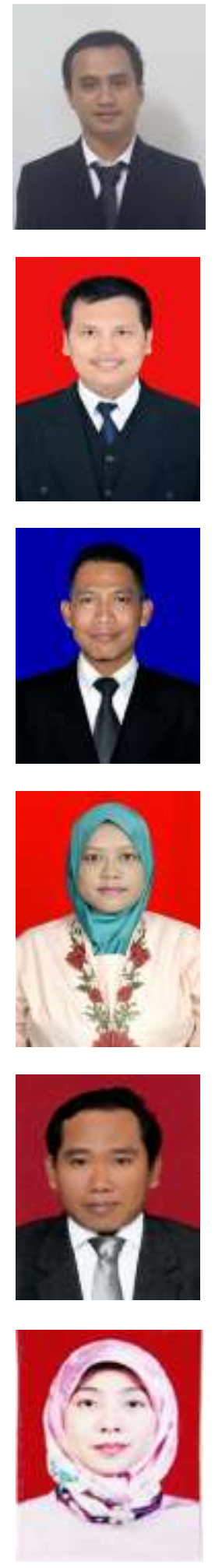

Freddy Artadima Silaban received his Master of Engineering (MT) degree in Electrical Engineering, Information Technology Specialization, Gunadarma University, Depok, 2016. He currently teaches at Universitas Mercu Buana, Jakarta (Indonesia). The focus of the research is an embedded system using control devices such as the FPGA, Arduino, and NodeMCU Modules. As well as IC design research using Xilinx ISE.

Lukman Medriavin Silalahi received his Master of Engineering (MT) degree in Electrical Engineering, Microwave Technology, Universitas Mercu Buana, Jakarta, 2017. He currently teaches at Universitas Mercu Buana, Jakarta (Indonesia). The focus of research is mobile telecommunications and embedded systems.

Selamet Kurniawan received his Master of Engineering (MT) degree in Electrical Engineering, Microwave Technology, Universitas Mercu Buana, Jakarta.

Fajar Rahayu I. M received his Master of Engineering (MT) degree in Electrical Engineering, Microwave Technology, Universitas Indonesia, Jakarta. She currently teaches at Universitas Pembangunan Nasional Indonesia.

Ucuk Darusalam received his Ph.D in Electrical Engineering, Universitas Indonesia. He currently teaches at Universitas Nasional, Jakarta (Indonesia).

Septi Andryana received his Ph.D in Electrical Engineering, Universitas Gunadarma, She currently teaches at Universitas Nasional, Jakarta (Indonesia). 